\title{
Sustainable Hydrogenation of Vinyl Derivatives Using Pd/C Catalysts
}

\author{
Roman M. Mironenko ${ }^{1}$, Elina R. Saybulina ${ }^{1}$, Liudmila N. Stepanova ${ }^{1}$, Tatiana I. Gulyaeva ${ }^{1}$, \\ Mikhail V. Trenikhin ${ }^{1}$, Konstantin S. Rodygin ${ }^{2}$ and Valentine P. Ananikov ${ }^{3, *}$ (D) \\ 1 Center of New Chemical Technologies BIC, Neftezavodskaya st. 54, 644040 Omsk, Russia; \\ mironenko@ihcp.ru (R.M.M.); e.r.saybulina@chemomsu.ru (E.R.S.); lchem@yandex.ru (L.N.S.); \\ tangul-8790@ihcp.ru (T.I.G.); tremv@yandex.ru (M.V.T.) \\ 2 Institute of Chemistry, Saint Petersburg State University, Universitetskiy pr. 26, \\ 198504 Saint Petersburg, Russia; k.rodygin@spbu.ru \\ 3 N. D. Zelinsky Institute of Organic Chemistry, Leninsky pr. 47, 119991 Moscow, Russia \\ * Correspondence: val@ioc.ac.ru; Tel.: +7-499-135-9079
}

Citation: Mironenko, R.M Saybulina, E.R; Stepanova, L.N; Gulyaeva, T.I; Trenikhin, M.V; Rodygin, K.S; Ananikov, V.P Sustainable Hydrogenation of Vinyl Derivatives Using Pd/C Catalysts. Catalysts 2021, 11, 179. https:// doi.org/10.3390/catal11020179

Academic Editors: Luis M. Martínez-Prieto and Patricia Lara Received: 29 December 2020

Accepted: 26 January 2021

Published: 28 January 2021

Publisher's Note: MDPI stays neutral with regard to jurisdictional claims in published maps and institutional affiliations.

Copyright: (c) 2021 by the authors. Licensee MDPI, Basel, Switzerland. This article is an open access article distributed under the terms and conditions of the Creative Commons Attribution (CC BY) license (https:// creativecommons.org/licenses/by/ $4.0 /)$.

\begin{abstract}
The hydrogenation of unsaturated double bonds with molecular hydrogen is an efficient atom-economic approach to the production of a wide range of fine chemicals. In contrast to a number of reducing reagents typically involved in organic synthesis, hydrogenation with $\mathrm{H}_{2}$ is much more sustainable since it does not produce wastes (i.e., reducing reagent residues). However, its full sustainable potential may be achieved only in the case of easily separable catalysts and high reaction selectivity. In this work, various $\mathrm{Pd} / \mathrm{C}$ catalysts were used for the liquid-phase hydrogenation of O-, S-, and N-vinyl derivatives with molecular hydrogen under mild reaction conditions (room temperature, pressure of $1 \mathrm{MPa})$. Complete conversion and high hydrogenation selectivity (>99\%) were achieved by adjusting the type of $\mathrm{Pd} / \mathrm{C}$ catalyst. Thus, the proposed procedure can be used as a sustainable method for vinyl group transformation by hydrogenation reactions. The discovery of the stability of active vinyl functional groups conjugated with heteroatoms $(\mathrm{O}, \mathrm{S}$, and $\mathrm{N})$ under hydrogenation conditions over $\mathrm{Pd} / \mathrm{C}$ catalysts opens the way for many useful transformations.
\end{abstract}

Keywords: molecular hydrogen; hydrogenation; Pd/C catalysts; calcium carbide; acetylene; vinyl group

\section{Introduction}

Sustainable development strategies and advanced next-generation chemical processes are important challenges for industry in the 21st century. The design of modern industrial processes must necessarily include sustainability principles [1-3]. The rates and scales of the mining of fossils led to revision of the criteria for manufacturing efficiency, followed by a shift in focus from the largest amounts in favor of waste reduction and atom economy [4,5]. The exhaustion of available reserves and dispelling of the myth of endless fossil resources have brought sustainability to the forefront.

Improvement of the existing methods and development of new ones for the conversion of biomass-derived building blocks into valuable fine chemicals plays a crucial role in sustainable development projects. The construction of molecules from bio-derived blocks, as well as biofuel production, has a key advantage over the use of hydrocarbons [6-9]. Biomass is a rapidly renewable resource, access to which opens a number of sustainable opportunities.

The construction of closed carbon-neutral cycles [10], including the stages of synthesis, application, utilization, and regeneration of carbon-containing molecules, has a fundamentally important role [11]. We previously showed that the conceptual possibility of constructing closed carbon-neutral cycles is provided by atom-economical addition reactions based on calcium carbide (Scheme 1) [12]. Calcium carbide can be obtained by cyclic technology using lime (calcium carbonate and calcium oxide) and various sources 
of elemental carbon (regenerated carbon, bioderived carbon, coke, charcoal, anthracite, etc.) $[12,13]$. Acetylene, the simplest alkyne, released during hydrolysis is a molecule of choice for a sequence of atom-economic addition reactions. Available positions with an unsaturated bond can be filled with the desired blocks in the required sequence.

Step 1: known

$\mathrm{CaC}_{2}$ sustainable cycle

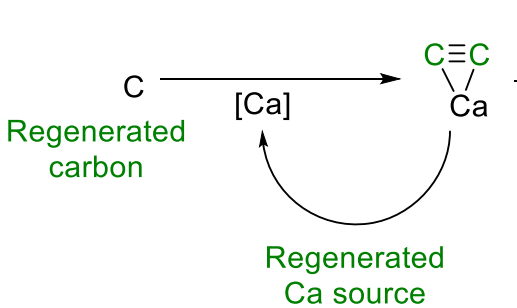

Step 2: known

Functionalization
Step 3: this work

Hydrogenation

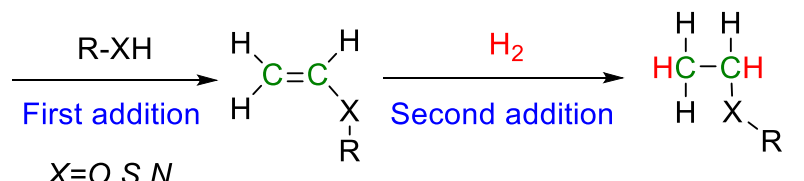

Scheme 1. An example of the possible implementation of carbon-neutral technology based on the calcium carbide cycle, functionalization, and hydrogenation.

The closed $\mathrm{CaC}_{2}$ loop was previously described in detail (Step 1, Scheme 1) [10,11]. Methodological approaches for the next step (Step 2, Scheme 1) have been well developed, targeting the implementation of waste-free atom-economical reactions of the addition of functional groups $\mathrm{O}-\mathrm{H}[14-17], \mathrm{S}-\mathrm{H}[18]$, and $\mathrm{N}-\mathrm{H}[19,20]$ to calcium carbide and obtaining the corresponding valuable vinyl derivatives [12]. The nucleophilic addition proceeds under superbasic conditions in good yields without the use of gaseous acetylene and can be safely carried out in a laboratory. Labeled compounds with deuterium [21] and carbon ${ }^{13} \mathrm{C}$ [22] incorporation can also be obtained that increase applications in further transformations: polymerization [23], Heck-like reactions [24], cycloaddition [25,26], and many others. Here, we expand the scope of applications of vinyl derivatives and demonstrate that molecular hydrogen can be successfully added to functionalized vinyl derivatives.

For a full-scale study and assessment of the potential of this synthetic approach, it is necessary to carry out systematic investigations of the processes of further transformations of the resulting vinyl derivatives. Catalytic hydrogenation is the cornerstone of a series of waste-free, atom-efficient processes. Compared to chemical reduction methods, catalytic hydrogenation with molecular hydrogen has significant environmental advantages.

In this work, we investigated for the first time the catalytic hydrogenation of vinyl derivatives, namely, benzyl vinyl ether (BVE), nonyl vinyl ether (NVE), and dodecyl vinyl sulfide (DVS). Hydrogenation of these practically important compounds has not been previously reported and is a novel process studied here.

In addition, we also studied the hydrogenation of 9-vinylcarbazole (9-VC). Previously [27-29], it was shown that 9-ethylcarbazole (9-EC) can be obtained by reduction of 9-VC with hydrazine hydrate in the presence of metal catalysts. At the same time, there are very few data on the catalytic hydrogenation of 9-VC with molecular hydrogen [30,31].

The hydrogenation of $C=C$ bonds in vinyl derivatives can be accompanied by a side reaction-hydrogenolysis of the bond between the carbon and a heteroatom [32]. The relative rates of these reactions and, consequently, the selectivity for the target hydrogenation product largely depend on the composition of the catalyst. According to the literature [32,33], palladium catalysts are less active in hydrogenolysis than platinum systems under mild reaction conditions. The performance of $\mathrm{Pd} / \mathrm{C}$ catalysts in the hydrogenation of some vinyl ethers to the corresponding ethyl ethers was investigated in previous studies [34-38].

The use of Pd/C catalysts for the hydrogenation of organic compounds with molecular hydrogen is in demand not only in laboratory practice but also in the industrial production of fragrances, pesticides, pharmaceuticals, and dyes [39-41]. Carbon-supported palladium catalysts are currently among the most frequently used heterogeneous catalysts. Apparently, the main reasons for this are the huge variety of forms of carbon materials [42], as 
well as the many unique properties of palladium as a chemical element [43]. The high efficiency of $\mathrm{Pd} / \mathrm{C}$ catalysts in hydrogenation with the possibility of tuning selectivity is ensured when the physicochemical properties of the carbon surface and the structure of catalytically active sites are optimized [44]. In the present work, we used $\mathrm{Pd} / \mathrm{C}$ catalysts prepared using different carbon materials and palladium precursors.

\section{Results and Discussion}

\subsection{Characterization of Catalysts}

Catalyst supports, namely, multi-walled carbon nanotubes (MWCNTs) and nanoglobular carbons (carbon blacks) P278-E and T900, were characterized in previous works $[45,46]$ and used in the present study for the preparation of Pd/C catalysts. The MWCNT support $\left(S_{\mathrm{BET}}=213 \mathrm{~m}^{2} \mathrm{~g}^{-1}\right)$ exhibited a fiber-like morphology, and according to FTIR spectroscopy, its surface was depleted of oxygen functional groups. P278-E $\left(S_{\mathrm{BET}}=415 \mathrm{~m}^{2} \mathrm{~g}^{-1}\right)$ and T900 $\left(S_{\mathrm{BET}}=10 \mathrm{~m}^{2} \mathrm{~g}^{-1}\right)$ are nanostructured carbon materials consisting of aggregated globules with average diameters of 31 and $170 \mathrm{~nm}$, respectively. According to FTIR spectroscopy, the nanoglobular carbons differ to some extent in the intensity of the absorption bands corresponding to the $\mathrm{C}-\mathrm{O}$ stretching vibrations of various surface oxygen functionalities. P278-E nanoglobular carbon was produced by oxidative pyrolysis of aromatic hydrocarbons (furnace black process); therefore, its surface was enriched with oxygen functionalities. In addition, this carbon support exhibits noticeable Brønsted acidity in aqueous suspension ( $\mathrm{pH}$ of point of zero charge 6.1).

In the present study, the following readily available palladium compounds were chosen for the preparation of $\mathrm{Pd} / \mathrm{C}$ catalysts: $\mathrm{H}_{2}\left[\mathrm{PdCl}_{4}\right]$ (chloride complexes, CCs); $\mathrm{Pd}$ polynuclear hydroxo complexes (PHCs); palladium(II) acetate, $\left[\mathrm{Pd}(\mathrm{OAc})_{2}\right]_{3}$; and tris(dibenzylideneacetone)dipalladium $(0),\left[\mathrm{Pd}_{2}(\mathrm{dba})_{3}\right]$. These palladium precursors are very different in composition, and various conditions are required for their deposition on the carbon supports and for the formation of Pd nanoparticles (NPs).

According to TEM measurements and CO chemisorption data, the size of Pd NPs in the reduced $2 \% \mathrm{Pd} / \mathrm{C}$ catalysts depends both on the nature of the carbon support and on the composition of the palladium precursor (Figure 1, Table 1; see also Figures S2-S7). The $2 \%$ Pd-CCs /MWCNTs catalyst contained highly dispersed Pd NPs (average size of $2.2 \mathrm{~nm}$ ), whereas in the samples based on nanoglobular carbons, Pd NPs were noticeably larger in size. Among them, the P278-E-supported catalyst had dispersed Pd NPs with quite narrow size distribution (Figure 1b), while Pd NPs in the $2 \%$ Pd-CCs/T900 catalyst were larger in size with a wider distribution (Figure 1c). For the catalysts based on T900, the use of Pd PHCs, Pd acetate, and $\left[\mathrm{Pd}_{2}(\mathrm{dba})_{3}\right]$ as the palladium precursors led to the formation of larger Pd NPs compared to those in the Pd-CCs/T900 catalyst (Figure 1d-f; see also Table 1, entries 4-6). In addition, for the T900-supported catalysts prepared using precursors with organic ligands, there was a significant discrepancy between the TEM and CO chemisorption data. Thus, the $2 \% \mathrm{Pd}-\mathrm{Ac} / \mathrm{T} 900$ catalyst had a Pd dispersion that was too low, as measured from the chemisorption of $\mathrm{CO}$ (Table 1, entry 5). For the $2 \%$ Pd-dba/T900 sample, no chemisorption of CO was observed (Table 1, entry 6). This may be due to partial encapsulation of Pd NPs with amorphous carbon [44,47] caused by strong palladium-support interaction that is apparently enhanced with the presence of organic ligands. Obviously, such encapsulation limits the accessibility of palladium sites for the adsorption of reactant molecules. 

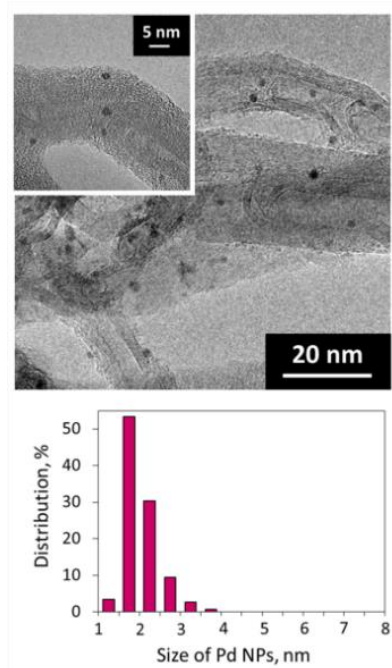

(a)
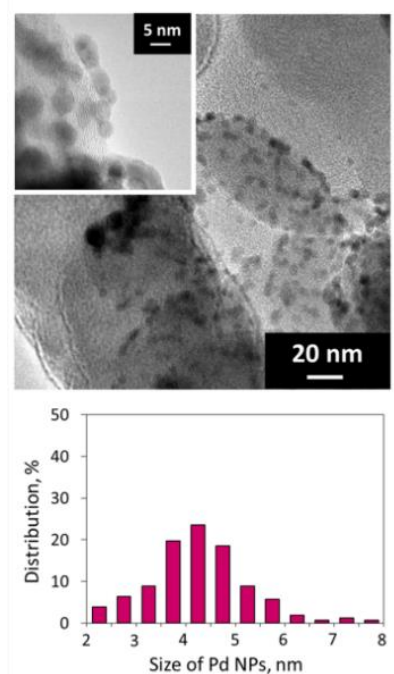

(d)
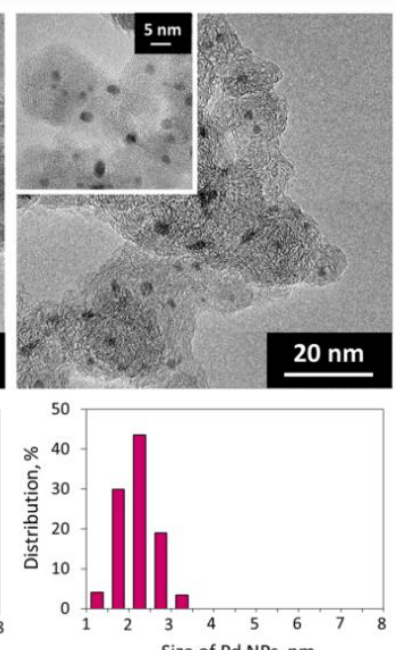

(b)
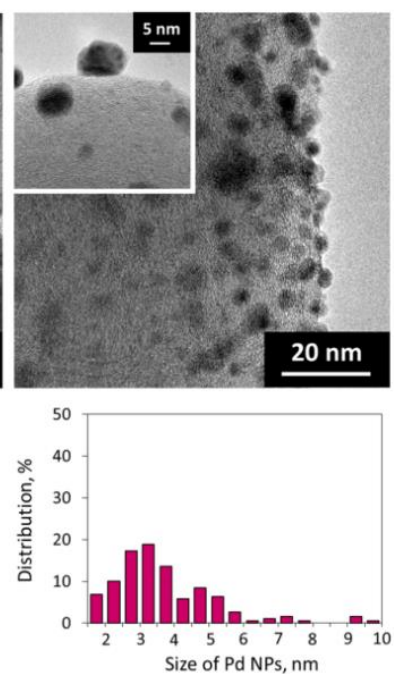

(e)
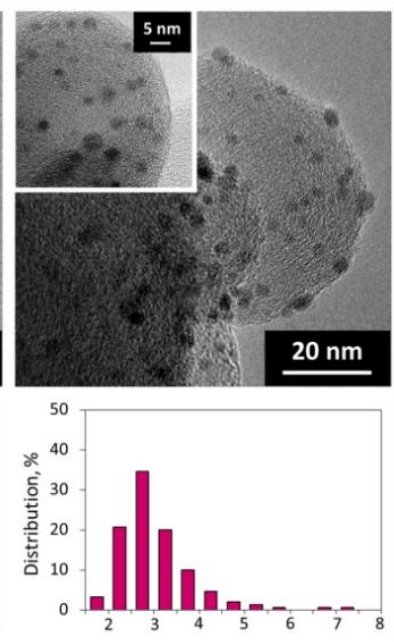

Size of Pd NPs, nm

(c)
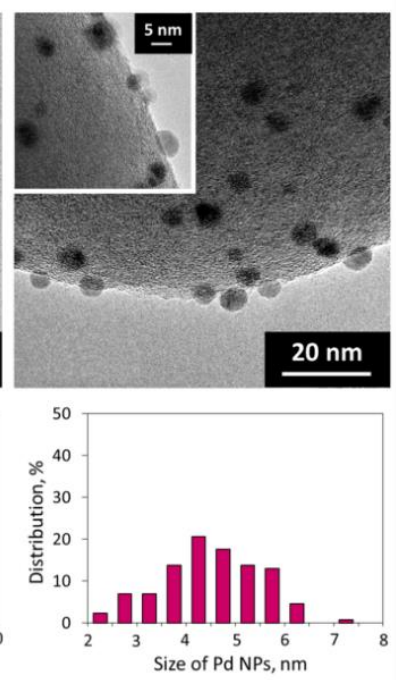

(f)

Figure 1. TEM images and the corresponding Pd nanoparticle (NP) size distribution histograms of the Pd/C catalysts: (a) 2\% Pd-CCs/MWCNTs; (b) 2\% Pd-CCs/P278-E; (c) 2\% Pd-CCs/T900; (d) 2\% Pd-PHCs/T900; (e) 2\% Pd-Ac/T900; (f) 2\% Pd-dba/T900.

Table 1. Palladium dispersion and average size of Pd NPs in Pd/C catalysts.

\begin{tabular}{cccccc}
\hline Entry & Catalyst & $\begin{array}{c}\text { Pd Content, } \\
\text { wt. } \mathbf{~}^{\mathbf{1}}\end{array}$ & Pd Dispersion $\mathbf{2}^{2}$ & $\begin{array}{c}\text { Average Size of Pd } \\
\text { NPs Estimated from } \\
\text { CO Chemisorption } \\
\text { Data, nm }\end{array}$ & $\begin{array}{c}\text { Average Size of Pd } \\
\text { NPs Determined by } \\
\text { TEM, nm }\end{array}$ \\
\hline 1 & $2 \%$ Pd-CCs/MWCNTs & 1.9 & 0.52 & 2.2 & 2.2 \\
2 & $2 \%$ Pd-CCs/P278-E & 2.1 & 0.30 & 3.7 & 2.4 \\
3 & $2 \%$ Pd-CCs/T900 & 2.0 & 0.28 & 4.0 & 4.3 \\
4 & $2 \%$ Pd-PHCs/T900 & 2.0 & 0.24 & 18.5 & 6.7 \\
5 & $2 \%$ Pd-Ac/T900 & 2.0 & 0.06 & - & 4.9 \\
6 & $2 \%$ Pd-dba/T900 & 2.1 & No chemisorption & \\
\hline
\end{tabular}

\footnotetext{
${ }^{1}$ According to ICP-AES or AAS analysis. ${ }^{2}$ According to $\mathrm{CO}$ chemisorption $(\mathrm{Pd} / \mathrm{CO}=2)$.
} 


\subsection{Effect of Carbon Support on the Activity and Selectivity of Pd/C Catalysts in the} Hydrogenation of Vinyl Derivatives

The $2 \%$ Pd-CCs /C catalysts prepared using MWCNTs, P278-E, and T900 as the supports were studied in the liquid-phase hydrogenation of vinyl derivatives $(20 \mathrm{mg}$ catalyst ( $3.8 \mu \mathrm{mol} \mathrm{Pd}$ ), $50 \mathrm{mg}$ substrate, $2.0 \mathrm{~mL} \mathrm{MeOH}$ or benzene, $295 \mathrm{~K}, 1.0 \mathrm{MPa}_{2}$ ) and showed significant differences in activity (substrate conversion after $2 \mathrm{~h}$ ) and selectivity (Figure 2). During the hydrogenation of BVE and NVE in MeOH solution (Figure 2a,b), the catalysts based on MWCNTs and P278-E ensured complete conversion of the substrates, and in addition to the products of $\mathrm{C}=\mathrm{C}$ bond hydrogenation-i.e., benzyl ethyl ether (BEE) and nonyl ethyl ether (NEE) - benzyl alcohol (BAL), nonyl alcohol (NAL), and 1,1-dimethoxyethane (DME) were also found in the reaction solutions.

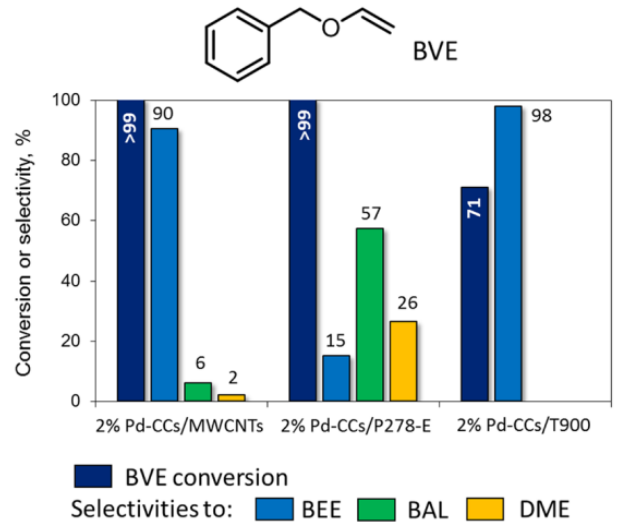

(a)

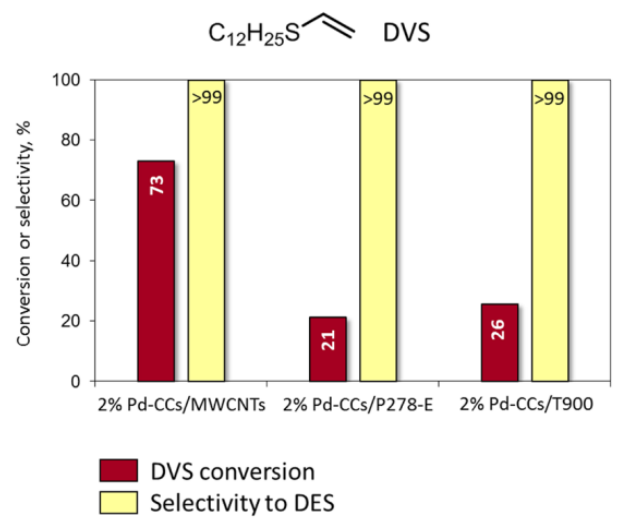

(c)

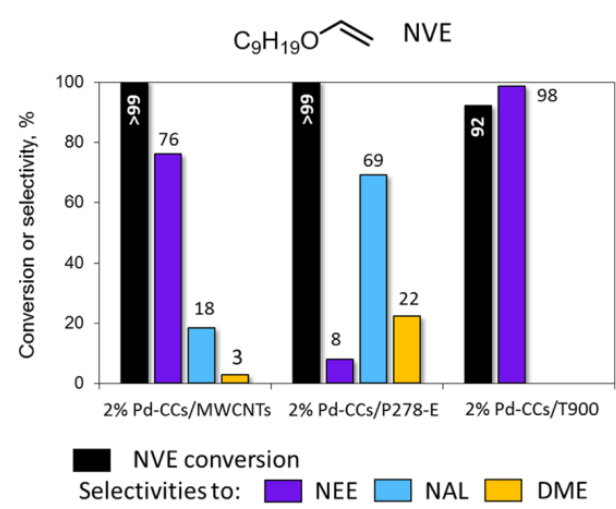

(b)

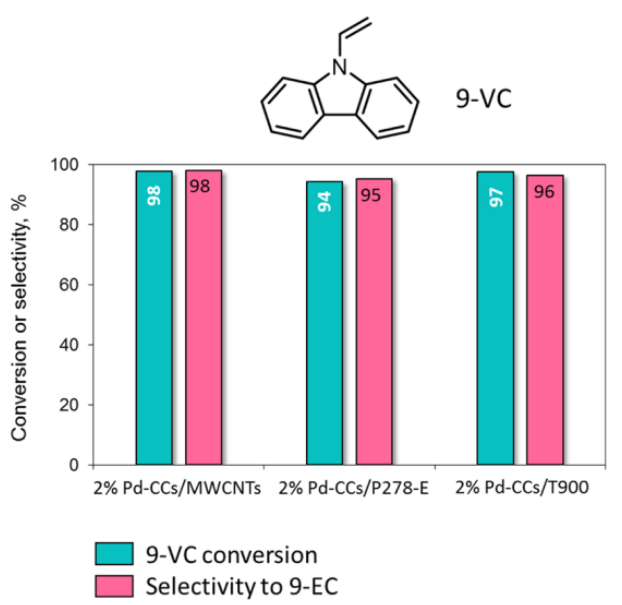

(d)

Figure 2. Catalytic performance of $2 \% \mathrm{Pd}-\mathrm{CCs} / \mathrm{C}$ catalysts based on different carbon supports in the liquid-phase hydrogenation of vinyl derivatives: (a) benzyl vinyl ether (BVE); (b) nonyl vinyl ether (NVE); (c) dodecyl vinyl sulfide (DVS); (d) 9-vinylcarbazole (9-VC). Reaction conditions: $20 \mathrm{mg}$ catalyst (50 mg 2\% Pd-CCs/T900 for hydrogenation of 9-VC), $50 \mathrm{mg}$ substrate, $2.0 \mathrm{~mL} \mathrm{MeOH}$ (benzene for hydrogenation of 9-VC), $295 \mathrm{~K}, 1.0 \mathrm{MPa} \mathrm{H}_{2}, 2 \mathrm{~h}$. The products were identified by NMR and GC-MS (see Supplementary Materials).

The reaction composition-time profiles obtained for the hydrogenation of BVE and NVE on the $2 \%$ Pd-CCs/P278-E catalyst (Figure 3), together with published data on ether chemistry [48], allowed us to suggest a reaction scheme for the conversion of these vinyl ethers in $\mathrm{MeOH}$ solution (Scheme 2). Vinyl ether is not only hydrogenated but can also react with methanol to form an intermediate acetal (1-benzyloxy-1-methoxyethane 
or 1-nonyloxy-1-methoxyethane) that undergoes transacetalization to the corresponding alcohol (BAL or NAL) and DME. The reactions with the solvent can be catalyzed by both palladium [38] and acidic sites [48]. In the presence of the 2\% Pd-CCs/P278-E catalyst, these reactions were most pronounced since the selectivities to BAL and NAL reached $57 \%$ and $69 \%$, respectively (Figure $2 a, b$ ). This could be explained by the increased content of acidic oxygen functionalities on the surface of P278-E, as noted above. However, the blank experiment using the P278-E support instead of a palladium catalyst did not show any conversion of BVE under the same reaction conditions. Therefore, we believe that the reactions with $\mathrm{MeOH}$ proceed on palladium sites located in a suitable environment of oxygen functionalities. The interaction of Pd clusters (or small Pd NPs) and protons of nearby acidic groups can result in the formation of $\left[\mathrm{Pd}_{n}-\mathrm{H}\right]^{+}$couples [49], which catalyze both hydrogenation and reactions with methanol. Apparently, the formation of such bifunctional active sites turned out to be most pronounced for the catalyst based on P278-E, in which Pd NPs were highly dispersed (Table 1) and the support was characterized by an increased content of acidic oxygen functionalities.

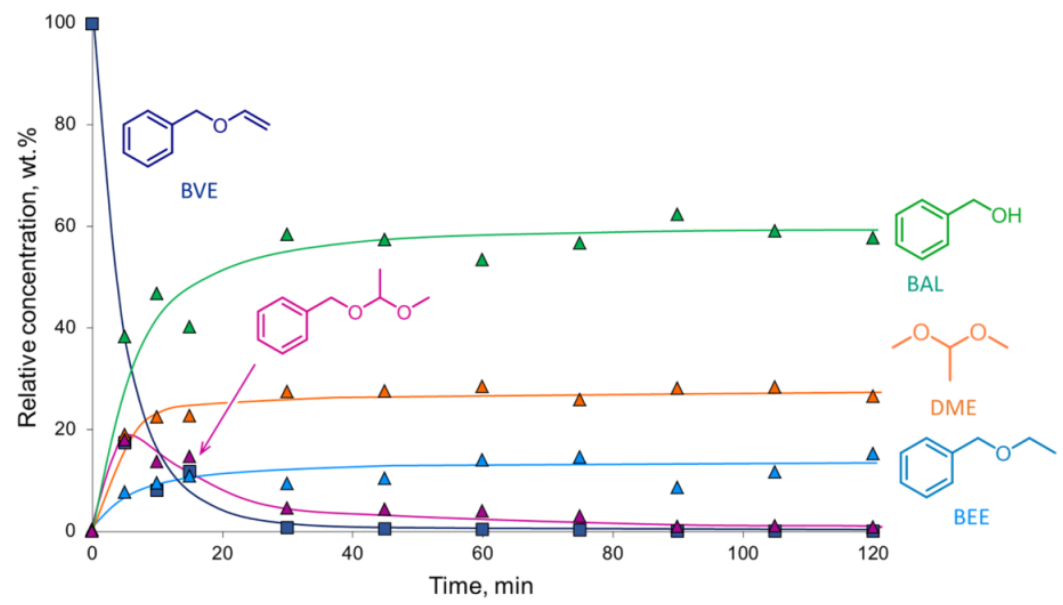

(a)

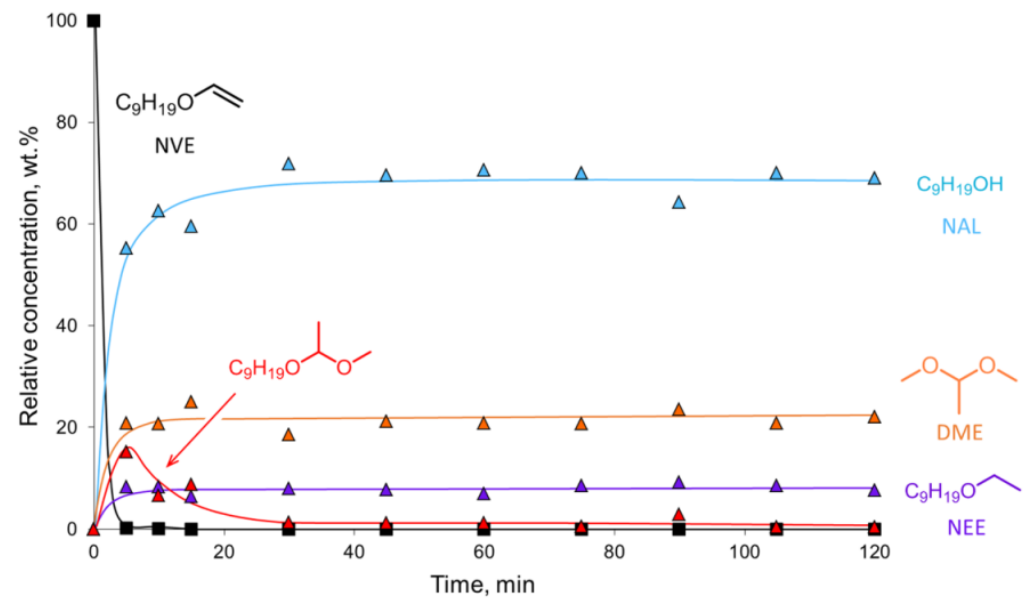

(b)

Figure 3. Reaction composition-time profiles of the hydrogenation of BVE (a) and NVE (b) over the $2 \%$ Pd-CCs/P278-E catalyst. Reaction conditions: $20 \mathrm{mg}$ catalyst ( $3.8 \mu \mathrm{mol} \mathrm{Pd}$ ), $50 \mathrm{mg}$ substrate, $2.0 \mathrm{~mL} \mathrm{MeOH}, 295 \mathrm{~K}, 1.0 \mathrm{MPa} \mathrm{H}_{2}$. The products were identified by NMR and GC-MS (see Supplementary Materials). 


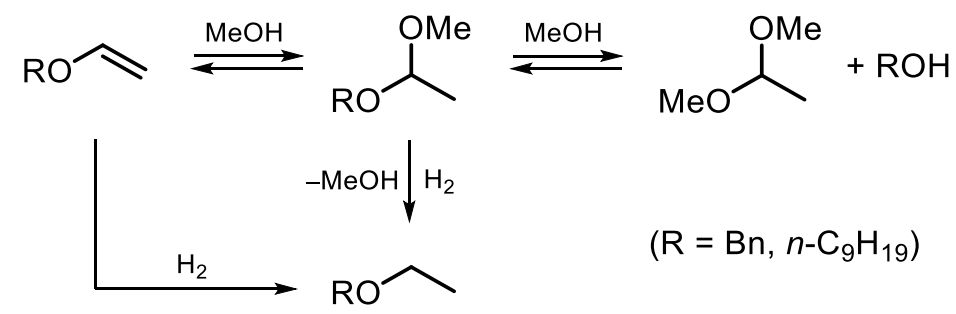

Scheme 2. Proposed reaction scheme for the hydrogenation of BVE and NVE over Pd/C catalysts in $\mathrm{MeOH}$ solution.

Note that methanol can act as a hydrogen donor and could thus participate in catalytic transfer hydrogenation $(\mathrm{CTH})$. To check this possibility, we carried out a catalytic test with $2 \%$ Pd-CCs/P278-E and BVE under the same conditions as above (MeOH, $295 \mathrm{~K}, 2 \mathrm{~h}$ ) but using argon instead of hydrogen. The BVE conversion was less than $2 \%$, indicating very low activity of the catalyst in CTH. Therefore, during hydrogenation of vinyl ethers under the chosen mild reaction conditions, hydrogen-transfer processes can be neglected.

The catalyst based on T900 was the least active in the hydrogenation of BVE and NVE (Figure 2a,b) since conversion of these substrates was incomplete after $2 \mathrm{~h}$ and, furthermore, no reaction with methanol occurred. As a result, high selectivity to BEE and NEE (98\%) was achieved. Increasing the loading of this catalyst from 20 to $50 \mathrm{mg}(9.5 \mu \mathrm{mol} P d$ instead of $3.8 \mu \mathrm{mol}$ ) ensured complete conversion of BVE and NVE, while the selectivity to the corresponding ethyl ethers remained high (>98\%).

The hydrogenation of DVS in the presence of the $2 \%$ palladium catalysts based on MWCNTs, P278-E, and T900 under the same reaction conditions did not proceed completely within $2 \mathrm{~h}$ (Figure 2c). The most active MWCNT-based catalyst provided 73\% conversion of the substrate. The least activity was shown by the $2 \%$ Pd-CCs/P278-E catalyst, in the presence of which the conversion was only $21 \%$. At the same time, during the hydrogenation of DVS, reactions with the participation of methanol did not occur, and dodecyl ethyl sulfide (DES) was the only conversion product (selectivity $>99 \%$ ).

The hydrogenation of 9-VC in benzene (Figure 2d) proceeded almost completely within $2 \mathrm{~h}$ (conversion >97\%) in the presence of the catalysts based on MWCNTs and T900, whereas the conversion of 9-VC was slightly lower (94\%) over the $2 \%$ Pd-CCs/P278-E catalyst. It is important that 9-VC hydrogenated to 9-EC with high selectivity (>95\%) regardless of the catalyst chosen.

To confirm the optimal content of palladium, we carried out the hydrogenation of all four vinyl derivatives in the presence of $1 \%$ Pd-CCs/T900 catalyst $(20 \mathrm{mg}, 1.9 \mu \mathrm{mol} \mathrm{Pd})$ under the typical hydrogenation conditions used in this work $(50 \mathrm{mg}$ substrate, $2.0 \mathrm{~mL}$ solvent, $295 \mathrm{~K}, 1.0 \mathrm{MPa} \mathrm{H}_{2}, 2 \mathrm{~h}$ ). It was found that this catalyst did not provide complete conversion of the substrates (BVE 71\%, NVE 87\%, DVS 31\%, 9-VC 91\%) but had a high selectivity for the corresponding ethyl derivatives (>99\%).

According to the results obtained, the reactivity of substrates increases in the order $\mathrm{DVS}<\mathrm{BVE}<9-\mathrm{VC} \approx \mathrm{NVE}$ under the same hydrogenation conditions and using the same catalyst. NVE, being one of the most reactive substrates, was rapidly converted on the $2 \%$ Pd-CCs $/$ P278-E catalyst within only $5 \mathrm{~min}\left(\mathrm{TOF}=3119 \mathrm{~h}^{-1}\right)$, while almost complete conversion of BVE was achieved after $30 \mathrm{~min}\left(\mathrm{TOF}=660 \mathrm{~h}^{-1}\right)$ (Figure 3).

\subsection{Effect of the Palladium Precursor Used for the Preparation of Pd/C Catalysts on Their Activity} and Selectivity in the Hydrogenation of Vinyl Derivatives

The $2 \% \mathrm{Pd} / \mathrm{T} 900$ catalysts prepared using various palladium precursors were studied in the liquid-phase hydrogenation of BVE, NVE, DVS, and 9-VC under the specified reaction conditions ( $50 \mathrm{mg}$ catalyst $(9.5 \mu \mathrm{mol} \mathrm{Pd}), 50 \mathrm{mg}$ substrate, $2.0 \mathrm{~mL}$ of $\mathrm{MeOH}$ or benzene, $295 \mathrm{~K}, 1.0 \mathrm{MPa} \mathrm{H}_{2}, 2 \mathrm{~h}$ ). It was found that the catalysts prepared from Pd CCs, PHCs, and acetate were highly active in the hydrogenation of BVE and NVE and provided almost complete conversion of the initial ethers with selective formation of the corresponding 
ethyl ethers (Figure $4 a, b)$. In the presence of the catalyst prepared using $\left[\operatorname{Pd}_{2}(\mathrm{dba})_{3}\right]$, the conversions of BVE and NVE were incomplete. The decreased activity of this catalyst may be associated with the poor accessibility of palladium sites for reactant molecules, which is apparently related to the partial encapsulation of Pd NPs by amorphous carbon (see Table 1).

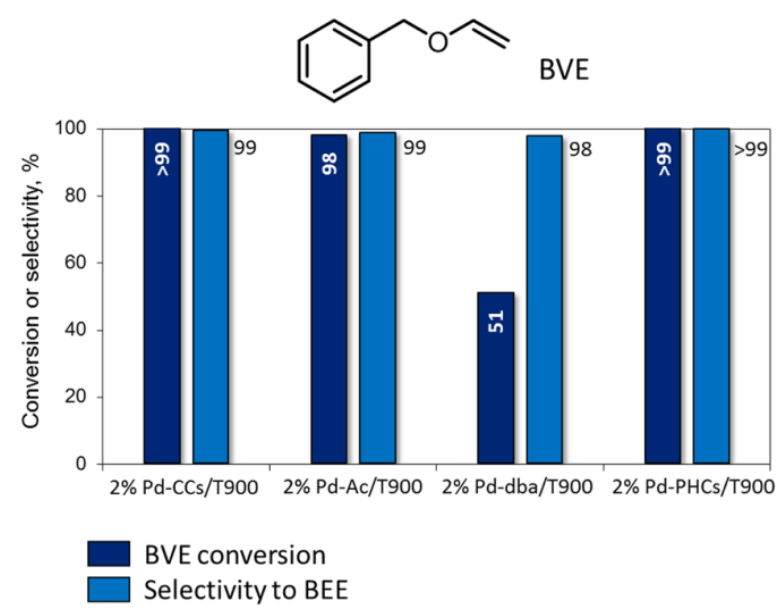

(a)

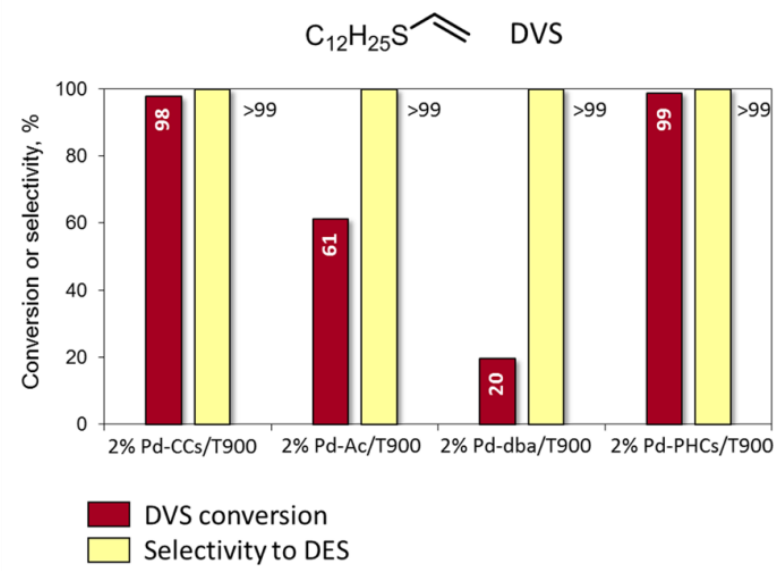

(c)

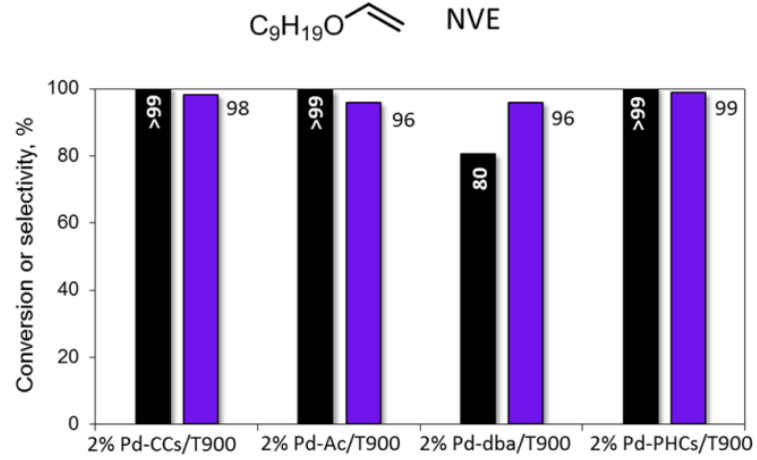

NVE conversion

Selectivity to NEE

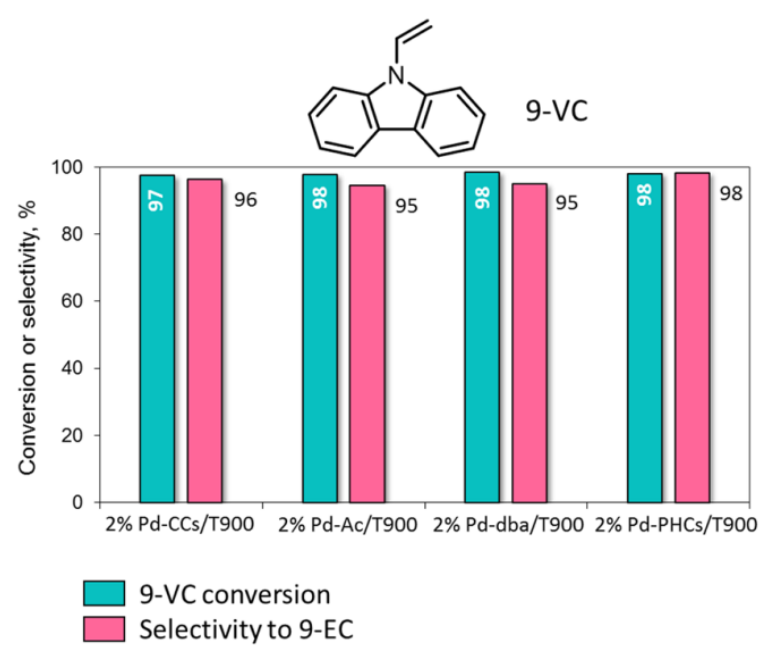

(d)

Figure 4. Catalytic performance of $2 \% \mathrm{Pd} / \mathrm{T} 900$ catalysts prepared from different palladium precursors in the liquid-phase hydrogenation of vinyl derivatives: (a) BVE; (b) NVE; (c) DVS; (d) 9-VC. Reaction conditions: 50 mg catalyst (9.5 $\mu \mathrm{mol}$ Pd), $50 \mathrm{mg}$ substrate, $2.0 \mathrm{~mL} \mathrm{MeOH}$ (benzene for hydrogenation of 9-VC), $295 \mathrm{~K}, 1.0 \mathrm{MPa} \mathrm{H}_{2}, 2 \mathrm{~h}$. The products were identified by NMR and GC-MS (see Supplementary Materials).

In the case of the hydrogenation of less-reactive DVS, the differences in the activity of the catalysts were even more noticeable (Figure 4c). The catalysts obtained from Pd CCs and PHCs provided almost complete conversion of DVS, whereas in the presence of $2 \%$ $\mathrm{Pd}-\mathrm{Ac} / \mathrm{T} 900$, the conversion was $61 \%$ due to the lower accessibility of palladium sites, as discussed above. When using the $2 \%$ Pd-dba/T900 catalyst, the DVS conversion did not exceed $20 \%$.

The hydrogenation of 9-VC (in benzene) proceeded almost completely $(>97 \%)$ regardless of the chosen catalyst, and high selectivity to 9-EC (>95\%) was always achieved (Figure 4d).

The $5 \% \mathrm{Pd} / \mathrm{T} 900$ catalysts prepared from Pd CCs, Pd PHCs, $\left[\mathrm{Pd}(\mathrm{OAc})_{2}\right]_{3}$, and $\left[\mathrm{Pd}_{2}(\mathrm{dba})_{3}\right]$ provided complete conversion of BVE and NVE to the corresponding ethyl ethers with 
high selectivity (>99\%) under the same hydrogenation conditions. It is important to note that when using all the catalysts based on the T900 support and containing both 2 and 5 wt.\% Pd, reactions with the solvent $(\mathrm{MeOH})$ did not occur, and selectivity to ethyl ethers exceeded $95 \%$.

The possibility of multiple uses of the catalyst was evaluated in five successive runs using 2\% Pd-PHCs/T900 as the catalyst and NVE as the substrate. The hydrogenation conditions were the same as those otherwise used in the work (50 mg catalyst, $50 \mathrm{mg}$ NVE, $\left.2.0 \mathrm{~mL} \mathrm{MeOH}, 295 \mathrm{~K}, 1.0 \mathrm{MPa} \mathrm{H}_{2}, 2 \mathrm{~h}\right)$. We applied the so-called "fresh start" technique [50,51], which means that after the completion of the reaction, the catalyst was not isolated and a fresh portion of the substrate (again $50 \mathrm{mg}$ ) was added to the reaction mixture. After that, the experiment was repeated. According to the results obtained (Figure 5), the catalyst showed excellent selectivity (>99\%) in all cycles. The yields were decreased, but remained at a good level $(>60 \%)$. We used the same experimental conditions for comparative purposes in this preliminary study, which indicated a potential for catalyst recycling. Further optimizations may be applied to improve the yields, which will be a subject of our future study. Of particular note, there were no pronounced changes in the catalyst structure (according to the TEM data of the spent catalyst, Figure S8). The decrease in activity may be associated with the partial deactivation of active sites [52,53].

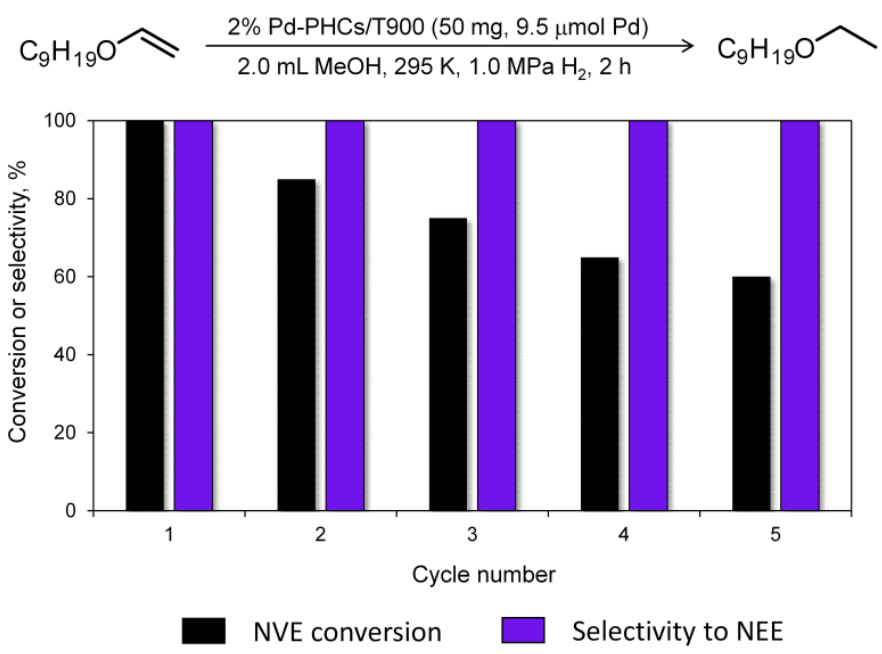

Figure 5. Reusability testing of the $2 \%$ Pd-PHCs/T900 catalyst in the hydrogenation of NVE.

\section{Materials and Methods}

\subsection{Materials and Reagents}

BVE, NVE, and DVS were synthesized from BAL, NAL, and 1-dodecanethiol, respectively, using calcium carbide as a vinylating agent [17,18]. 9-VC was purchased from Sigma-Aldrich (98\%, St. Louis, MO, USA) and used without further purification. All vinyl derivatives were stored in a refrigerator at $258 \mathrm{~K}$. Methanol (>99\%, Vekton, Saint Petersburg, Russia) and benzene (>99\%, EKOS-1, Moscow, Russia) were used as received.

For catalyst preparation, we used Baytubes ${ }^{\circledR}$ C 150 HP MWCNTs (Bayer Material Science AG, Leverkusen, Germany) characterized earlier [45,46], as well as furnace and thermal kinds of nanoglobular carbon (carbon blacks) P278-E and T900 (Department of Experimental Technologies, Center of New Chemical Technologies BIC). Palladium(II) chloride ( $>98 \%$, Aurat, Moscow, Russia) was used for catalyst preparation without any purification. $\left[\mathrm{Pd}(\mathrm{OAc})_{2}\right]_{3}$ and $\left[\mathrm{Pd}_{2}(\mathrm{dba})_{3}\right]$ were synthesized by known procedures [54]. The reduction of catalysts and catalytic hydrogenation were performed using hydrogen of high purity grade (99.99\%, NCCP, Novosibirsk, Russia). 


\subsection{Catalyst Preparation and Characterization}

The catalysts denoted as Pd-CCs/C (C = MWCNTs, P278-E, T900) were prepared by incipient wetness impregnation of the carbon supports with aqueous solutions of palladium CCs formed by dissolving $\mathrm{PdCl}_{2}$ in water containing an equimolar amount of $\mathrm{HCl}$. After deposition of Pd CCs on the supports, the samples were dried in air at room temperature and then at $393 \mathrm{~K}$. Before the experiments, the catalysts were reduced in flowing hydrogen at $573 \mathrm{~K}$ for $2 \mathrm{~h}$. Another procedure for catalyst preparation includes the adsorption of $\mathrm{Pd}$ PHCs onto carbon supports, as described in detail elsewhere [44,46]. A further reduction of supported Pd PHCs was performed in sodium formate solution at $363 \mathrm{~K}$ for $0.5 \mathrm{~h}$. The catalysts obtained by this method were denoted as Pd-PHCs/C. The catalysts denoted as $\mathrm{Pd}-\mathrm{Ac} / \mathrm{C}$ and $\mathrm{Pd}-\mathrm{dba} / \mathrm{C}$ were prepared by incipient wetness impregnation of the carbon supports with solutions of $\left[\mathrm{Pd}(\mathrm{OAc})_{2}\right]_{3}$ and $\left[\mathrm{Pd}_{2}(\mathrm{dba})_{3}\right]$ in $\mathrm{CHCl}_{3}$, as described earlier [52]. After deposition of these precursors, the samples were dried in air at room temperature and then at $393 \mathrm{~K}$. Before the experiments, the catalysts were reduced with hydrogen at $573 \mathrm{~K}$ for $2 \mathrm{~h}$.

The Pd dispersion in the reduced catalysts was estimated by pulse chemisorption of CO (>99.999 vol.\% purity) using an AutoChem II 2920 (Micromeritics, Norcross, GA, USA) instrument. The dispersion values were calculated assuming a stoichiometric $\mathrm{Pd} / \mathrm{CO}$ ratio of $2[55,56]$. The average volume-surface diameter $d_{\mathrm{av}}$ (in nanometers) of the Pd NPs was calculated from the Pd dispersion as $d_{\mathrm{av}}=1.11 / D$ [57].

TEM images of the reduced catalysts were taken by a JEM-2100 (JEOL, Tokyo, Japan) instrument with a lattice resolution of $0.145 \mathrm{~nm}$ at an accelerating voltage of $200 \mathrm{kV}$. The average volume-surface diameter of the Pd NPs was determined by measuring the size of more than 130 NPs and calculating by the equation $[57,58]$

$$
d_{\mathrm{av}}=\frac{\sum_{i} n_{i} d_{i}^{3}}{\sum_{i} n_{i} d_{i}^{2}}
$$

where $n_{i}$ is the number of Pd NPs counted in intervals of mean diameter $d_{i}$.

The palladium content in the catalysts was measured either by ICP-AES on a Varian 710-ES (Agilent Technologies, Santa Clara, CA, USA) spectrometer or by AAS on an AA6300 (Shimadzu, Kyoto, Japan) spectrometer. Before measurements, the catalysts were completely dissolved in a mixture of concentrated $\mathrm{HNO}_{3}$ and $\mathrm{HClO}_{4}$. The Pd content in the catalyst samples was 2 or 5 wt. $\%$.

\subsection{Hydrogenation of Vinyl Derivatives and Analysis of Reaction Products}

Catalytic hydrogenation of the selected vinyl derivatives was performed using a multireactor setup consisting of 9 steel autoclaves and a hydrogen supply system (see Figure S1 in Supplementary Materials). Glass vials loaded with $2.0 \mathrm{~mL}$ of substrate solution (50 mg substrate in methanol; in the case of 9-VC, benzene was used as a solvent), 20 or $50 \mathrm{mg}$ of catalyst (3.8 or $9.5 \mu \mathrm{mol} \mathrm{Pd}$, respectively), and magnetic stir bars were placed in autoclaves. Before the experiment, the autoclaves were flushed with argon to remove air and then filled with hydrogen to a pressure of $1.0 \mathrm{MPa}$. All experiments were carried out at room temperature $(295 \mathrm{~K})$ under vigorous stirring of the reaction mixtures using magnetic stirrers. After completion of the reaction (typically $2 \mathrm{~h}$ ), the reaction solutions were separated from the catalysts by filtration. Note that in preliminary tests carried out with a smaller amount of catalyst $(5 \mathrm{mg})$ and at a lower hydrogen pressure $(0.5 \mathrm{MPa})$, the conversions of vinyl ethers proceeded very slowly, and only traces of hydrogenation products were found in the reaction solutions.

In the present study the reactions were analyzed by ${ }^{1} \mathrm{H}$ and ${ }^{13} \mathrm{C}$ NMR immediately after the separation of the catalysts without evaporation of solvents. The NMR spectra were recorded on an Avance- 400 (Bruker, Billerica, MA, USA) NMR spectrometer (400 MHz for ${ }^{1} \mathrm{H}$ and $101 \mathrm{MHz}$ for ${ }^{13} \mathrm{C}$ ) using the No-D NMR technique [59,60]. The J-modulated 
spin echo technique was employed to record all the ${ }^{13} \mathrm{C}$ NMR spectra. In the $J$-modulated ${ }^{13} \mathrm{C}$ NMR spectra, the methine $(\mathrm{CH})$ and methyl $\left(\mathrm{CH}_{3}\right)$ signals have opposite phase to those of the quaternary $(\mathrm{C})$ and methylene $\left(\mathrm{CH}_{2}\right)$ resonances. GC-MS was also used for the identification of the reaction products on an Agilent 5973N/6890N instrument (Santa Clara, CA, USA) equipped with an HP-5MS column. MS measurements were carried out using electron impact ionization at $70 \mathrm{eV}$.

The quantitative determination of the reaction products was carried out by GC on a GKh-1000 (Khromos, Moscow, Russia) instrument equipped with a flame ionization detector. Analysis of the BVE and NVE conversion products was carried out using a ValcoBond VB-Wax (Poulsbo, WA, USA) capillary column $(60 \mathrm{~m} \times 0.32 \mathrm{~mm}$, polyethylene glycol, stationary phase thickness $0.50 \mu \mathrm{m}$ ). The oven temperature was programmed as follows: initial temperature of $323 \mathrm{~K}$ for $12 \mathrm{~min}$, increase of $10 \mathrm{~K} \mathrm{~min}^{-1}$ up to $513 \mathrm{~K}$, hold for $31 \mathrm{~min}$. The DVS and 9-VC conversion products were analyzed using an Agilent DB-1 (Santa Clara, CA, USA) capillary column $(100 \mathrm{~m} \times 0.25 \mathrm{~mm}$, dimethylpolysiloxane, stationary phase thickness $0.50 \mu \mathrm{m}$ ). In this case, the oven temperature was programmed as follows: initial temperature of $313 \mathrm{~K}$ for $1 \mathrm{~min}$, increase of $8 \mathrm{~K} \mathrm{~min}^{-1}$ up to $503 \mathrm{~K}$, hold for $60 \mathrm{~min}$.

The substrate conversion $X(\%)$ and selectivity to each product $S_{\mathrm{p}}(\%)$ were calculated as follows:

$$
\begin{aligned}
X & =\frac{n_{\mathrm{s}, 0}-n_{\mathrm{s}}}{n_{\mathrm{s}, 0}} \cdot 100 \\
S_{\mathrm{p}} & =\frac{n_{\mathrm{p}}}{\left(n_{\mathrm{s}, 0}-n_{\mathrm{s}}\right)} \cdot 100
\end{aligned}
$$

where $n_{\mathrm{s}, 0}, n_{\mathrm{s}}$, and $n_{\mathrm{p}}$ are the amounts (in moles) of substrate before the reaction, substrate after the reaction, and the reaction product, respectively.

\section{Conclusions}

Hydrogenation with molecular hydrogen is a versatile tool for both industrial production and fine organic synthesis. The uniqueness of molecular hydrogen as a hydrogenating agent is governed by (i) its powerful potential for sustainability due to its availability through the water splitting process; (ii) waste-free concepts, since the addition reactions are atom-economic; and (iii) access to easily separable heterogeneous catalysts that operate with high selectivity.

In this work, we tested a full sequence of addition reactions to the unsaturated $\mathrm{C}_{2}$ acetylenic unit (Scheme 1). Carbon-based palladium catalysts were very efficient in the liquid-phase hydrogenation of $\mathrm{O}_{-}, \mathrm{S}-$-, and $\mathrm{N}$-vinyl derivatives (benzyl vinyl ether, nonyl vinyl ether, dodecyl vinyl sulfide, and 9-vinylcarbazole) with molecular hydrogen under mild reaction conditions (room temperature, pressure of $1 \mathrm{MPa}$ ). Varying the carbon support and the palladium precursor used for catalyst preparation allowed us to flexibly regulate the activity and selectivity of $\mathrm{Pd} / \mathrm{C}$ catalysts in the hydrogenation of vinyl derivatives. The catalysts supported on nanoglobular carbon T900 and containing $2 \%$ or $5 \%$ palladium provided hydrogenation without side reactions, and the corresponding ethyl ethers were obtained with high selectivity ( $>95 \%)$.

The present study has shown the compatibility of vinyl functional groups attached to heteroatoms $(X=O, S, N)$ with hydrogenation conditions and the possibility of suppressing $\mathrm{C}-\mathrm{X}$ bond hydrogenolysis side reactions. Efficient transformation using $\mathrm{Pd} / \mathrm{C}$ catalysts opens the way for many useful practical applications.

Supplementary Materials: The following are available online at https:/ /www.mdpi.com/2073-4 344/11/2/179/s1. Figure S1: Multi-reactor setup used for liquid-phase hydrogenation of vinyl derivatives under hydrogen pressure. Figures S2-S8: TEM images of Pd/C catalysts. Results of identification of the hydrogenation products $\left({ }^{1} \mathrm{H} N \mathrm{NM},{ }^{13} \mathrm{C}\right.$ NMR, and MS data).

Author Contributions: R.M.M.: conceptualization and methodology, investigation, resources, writingoriginal draft preparation, review and editing, visualization; E.R.S.: investigation, resources, writing- 
review and editing; L.N.S., T.I.G., M.V.T.: investigation, writing-review and editing; K.S.R.: conceptualization and methodology, resources, visualization, writing-original draft preparation, review and editing; V.P.A.: conceptualization and methodology, writing-original draft preparation, review and editing, supervision. All authors have read and agreed to the published version of the manuscript.

Funding: This work was supported by the Ministry of Science and Higher Education of the Russian Federation within the governmental order for BIC (project AAAA-A21-121011490008-3), Scientific Schools Development Program by Zelinsky Institute of organic chemistry is gratefully acknowledged for partial support.

Data Availability Statement: Data are contained in the article and Supplementary Materials. Any additional data are available on request from the corresponding author.

Acknowledgments: We thank O.V. Maevskaya, R.R. Izmailov, E.N. Kudrya, S.N. Evdokimov, Y.A. Chumachenko, and V.A. Koveza for their able assistance with experiments. The authors are grateful to A.V. Pronin and I.V. Rezanov for technical support. The authors also wish to thank V.L. Yurpalov and A.V. Lavrenov for helpful discussion of the results. The research was performed using equipment of the Omsk Regional Center of Collective Usage, Siberian Branch of the Russian Academy of Sciences, and facilities of the shared research center "National Center of Investigation of Catalysts" at BIC.

Conflicts of Interest: The authors declare no conflict of interest.

\section{References}

1. Zimmerman, J.B.; Anastas, P.T.; Erythropel, H.C.; Leitner, W. Designing for a green chemistry future. Science 2020, 367, 397-400. [CrossRef] [PubMed]

2. Sheldon, R.A. Green and sustainable manufacture of chemicals from biomass: State of the art. Green Chem. 2014, 16, 950-963. [CrossRef]

3. Sheldon, R.A. Engineering a more sustainable world through catalysis and green chemistry. J. R. Soc. Interface 2016, $13,20160087$. [CrossRef] [PubMed]

4. Trost, B.M. The atom economy-A search for synthetic efficiency. Science 1991, 254, 1471-1477. [CrossRef] [PubMed]

5. Trost, B.M. On Inventing Reactions for Atom Economy. Acc. Chem. Res. 2002, 35, 695-705. [CrossRef]

6. Ragauskas, A.J.; Williams, C.K.; Davison, B.H.; Britovsek, G.; Cairney, J.; Eckert, C.A.; Frederick, W.J.; Hallett, J.P.; Leak, D.J.; Liotta, C.L.; et al. The Path Forward for Biofuels and Biomaterials. Science 2006, 311, 484-489. [CrossRef]

7. Himmel, M.E.; Ding, S.-Y.; Johnson, D.K.; Adney, W.S.; Nimlos, M.R.; Brady, J.W.; Foust, T.D. Biomass Recalcitrance: Engineering Plants and Enzymes for Biofuels Production. Science 2007, 315, 804-807. [CrossRef]

8. Somerville, C.; Youngs, H.; Taylor, C.; Davis, S.C.; Long, S.P. Feedstocks for Lignocellulosic Biofuels. Science 2010, 329, 790-792. [CrossRef]

9. Peralta-Yahya, P.P.; Zhang, F.; Del Cardayre, S.B.; Keasling, J.D. Microbial engineering for the production of advanced biofuels. Nature 2012, 488, 320-328. [CrossRef]

10. Rodygin, K.S.; Vikenteva, Y.A.; Ananikov, V.P. Calcium-Based Sustainable Chemical Technologies for Total Carbon Recycling. ChemSusChem 2019, 12, 1483-1516. [CrossRef]

11. Rodygin, K.S.; Lotsman, K.A.; Ananikov, V.P. Calcium Carbide Looping System for Acetaldehyde Manufacturing from Virtually any Carbon Source. ChemSusChem 2020, 13, 3679-3685. [CrossRef] [PubMed]

12. Rodygin, K.S.; Ledovskaya, M.S.; Voronin, V.V.; Lotsman, K.A.; Ananikov, V.P. Calcium Carbide: Versatile Synthetic Applications, Green Methodology and Sustainability. Eur. J. Org. Chem. 2021, 2021, 43-52. [CrossRef]

13. Kim, C.S.; Baddour, R.F.; Howard, J.B.; Meissner, H.P. $\mathrm{CaC}_{2}$ Production from $\mathrm{CaO}$ and Coal or Hydrocarbons in a Rotating-Arc Reactor. Ind. Eng. Chem. Process Des. Dev. 1979, 18, 323-328. [CrossRef]

14. Matake, R.; Adachi, Y.; Matsubara, H. Synthesis of vinyl ethers of alcohols using calcium carbide under superbasic catalytic conditions (KOH/DMSO). Green Chem. 2016, 18, 2614-2618. [CrossRef]

15. Teong, S.P.; Chua, A.Y.H.; Deng, S.; Li, X.; Zhang, Y. Direct vinylation of natural alcohols and derivatives with calcium carbide. Green Chem. 2017, 19, 1659-1662. [CrossRef]

16. Teong, S.P.; Lim, J.; Zhang, Y. Vinylation of Aryl Ether (Lignin $\beta-O-4$ Linkage) and Epoxides with Calcium Carbide through C-O Bond Cleavage. ChemSusChem 2017, 10, 3198-3201. [CrossRef]

17. Werner, G.; Rodygin, K.S.; Kostin, A.A.; Gordeev, E.G.; Kashin, A.S.; Ananikov, V.P. A solid acetylene reagent with enhanced reactivity: Fluoride-mediated functionalization of alcohols and phenols. Green Chem. 2017, 19, 3032-3041. [CrossRef]

18. Rodygin, K.S.; Ananikov, V.P. An efficient metal-free pathway to vinyl thioesters with calcium carbide as the acetylene source. Green Chem. 2016, 18, 482-486. [CrossRef]

19. Rattanangkool, E.; Vilaivan, T.; Sukwattanasinitt, M.; Wacharasindhu, S. An Atom-Economic Approach for Vinylation of Indoles and Phenols Using Calcium Carbide as Acetylene Surrogate. Eur. J. Org. Chem. 2016, 2016, 4347-4353. [CrossRef] 
20. Rodygin, K.S.; Bogachenkov, A.S.; Ananikov, V.P. Vinylation of a Secondary Amine Core with Calcium Carbide for Efficient Post-Modification and Access to Polymeric Materials. Molecules 2018, 23, 648. [CrossRef]

21. Ledovskaya, M.S.; Voronin, V.V.; Rodygin, K.S.; Posvyatenko, A.V.; Egorova, K.S.; Ananikov, V.P. Direct Synthesis of DeuteriumLabeled O-, S-, N-Vinyl Derivatives from Calcium Carbide. Synthesis 2019, 51, 3001-3013. [CrossRef]

22. Ledovskaya, M.S.; Voronin, V.V.; Rodygin, K.S.; Ananikov, V.P. Efficient labeling of organic molecules using ${ }^{13} \mathrm{C}$ elemental carbon: Universal access to ${ }^{13} \mathrm{C}_{2}$-labeled synthetic building blocks, polymers and pharmaceuticals. Org. Chem. Front. 2020, 7, 638-647. [CrossRef]

23. Kirillov, E.; Rodygin, K.; Ananikov, V. Recent advances in applications of vinyl ether monomers for precise synthesis of custom-tailored polymers. Eur. Polym. J. 2020, 136, 109872. [CrossRef]

24. Hachem, M.; Schneider, C.; Hoarau, C. Direct Stereoselective $\beta$-Arylation of Enol Ethers by a Decarboxylative Heck-Type Reaction. Eur. J. Org. Chem. 2020, 2020, 2052-2061. [CrossRef]

25. Jensen, K.B.; Roberson, M.; Jørgensen, K.A. Catalytic Enantioselective 1,3-Dipolar Cycloaddition Reactions of Cyclic Nitrones: A Simple Approach for the Formation of Optically Active Isoquinoline Derivatives. J. Org. Chem. 2000, 65, 9080-9084. [CrossRef]

26. Inoue, H.; Phan Thi Thanh, N.; Fujisawa, I.; Iwasa, S. Synthesis of Forms of a Chiral Ruthenium Complex Containing a Ru$\mathrm{C}_{\text {olefin }}\left(\mathrm{sp}^{2}\right)$ Bond and Their Application to Catalytic Asymmetric Cyclopropanation Reactions. Org. Lett. 2020, 22, 1475-1479. [CrossRef]

27. Lin, J.; Chen, J.; Su, W. Rhodium-cobalt bimetallic nanoparticles: A catalyst for selective hydrogenation of unsaturated carboncarbon bonds with hydrous hydrazine. Adv. Synth. Catal. 2013, 355, 41-46. [CrossRef]

28. Dhakshinamoorthy, A.; Navalon, S.; Sempere, D.; Alvaro, M.; Garcia, H. Reduction of alkenes catalyzed by copper nanoparticles supported on diamond nanoparticles. Chem. Commun. 2013, 49, 2359-2361. [CrossRef]

29. Mondal, J.; Nguyen, K.T.; Jana, A.; Kurniawan, K.; Borah, P.; Zhao, Y.; Bhaumik, A. Efficient alkene hydrogenation over a magnetically recoverable and recyclable $\mathrm{Fe}_{3} \mathrm{O}_{4} @ \mathrm{GO}$ nanocatalyst using hydrazine hydrate as the hydrogen source. Chem. Commun. 2014, 50, 12095-12097. [CrossRef]

30. Reppe, W. Vinylierung. Justus Liebigs Ann. Chem. 1956, 601, 81-138. [CrossRef]

31. Xu, Y.; Yao, Y.; Yu, H.; Shi, B.; Gao, S.; Zhang, L.; Miller, A.L.; Fang, J.-C.; Wang, X.; Huang, K. Nanoparticle-encapsulated hollow porous polymeric nanosphere frameworks as highly active and tunable size-selective catalysts. ACS Macro Lett. 2019, 8 , 1263-1267. [CrossRef]

32. Rylander, P.N. Catalytic Hydrogenation over Platinum Metals; Academic Press: New York, NY, USA, 1967; pp. 444-449.

33. Nishimura, S. Handbook of Heterogeneous Catalytic Hydrogenation for Organic Synthesis; John Wiley \& Sons: New York, NY, USA, 2001.

34. Boudjouk, P.; Han, B.-H. Palladium-catalyzed and sonically accelerated hydrogenations of olefins using formic acid as a hydrogen transfer agent. J. Catal. 1983, 79, 489-492. [CrossRef]

35. Kim, T.Y.; Yim, E.S.; Lee, S.J.; Park, M.K.; Han, B.H. Organic sonochemistry. Ultrasonically promoted hydrogenation of olefin. J. Korean Chem. Soc. 1996, 40, 216-218.

36. Koch, H.; Fischer, U. Verfahren zur Herstellung von Dialkylaminoethern. DE Patent 10,241,321, 18 March 2004.

37. Hughes, A.D.; Fleury, M.; Rapta, M.; Thalladi, V.R.; Fass, G.T.; Simeone, M.; Baldwin, R.M.; Bourdet, D.L. Crystalline (2S,4R)-5-(5'Chloro-2'-Fluoro-[1,1'-Biphenyl]-4-yl)-2-(Ethoxymethyl)-4-(3-Hydroxyisoxazole-5-Carboxamido)-2-Methylpentanoic Acid and Uses Thereof. Patent WO 2017/156009, 14 September 2017.

38. Itoh, H.; Yamamoto, E.; Masaoka, S.; Sakai, K.; Tokunaga, M. Kinetic resolution of P-chirogenic compounds by palladiumcatalyzed alcoholysis of vinyl ethers. Adv. Synth. Catal. 2009, 351, 1796-1800. [CrossRef]

39. Liu, X.; Astruc, D. Development of the applications of palladium on charcoal in organic synthesis. Adv. Synth. Catal. 2018, 360, 3426-3459. [CrossRef]

40. Sajiki, H.; Monguchi, Y. Development of palladium catalysts for chemoselective hydrogenation. In Pharmaceutical Process Chemistry; Shioiri, T., Izawa, K., Konoike, T., Eds.; Wiley-VCH: Weinheim, Germany, 2011; pp. 77-99.

41. Rase, H.F. Handbook of Commercial Catalysts: Heterogeneous Catalysts; CRC Press: Boca Raton, FL, USA, 2000; pp. 105-204.

42. Serp, P.; Machado, B. Nanostructured Carbon Materials for Catalysis; The Royal Society of Chemistry: Cambridge, UK, 2015.

43. Albéniz, A.C.; Espinet, P. Palladium: Inorganic \& Coordination Chemistry. In Encyclopedia of Inorganic Chemistry; King, R.B., Ed.; John Wiley \& Sons: Hoboken, NJ, USA, 2005.

44. Mironenko, R.M.; Belskaya, O.B.; Likholobov, V.A. Approaches to the synthesis of Pd/C catalysts with controllable activity and selectivity in hydrogenation reactions. Catal. Today 2020, 357, 152-165. [CrossRef]

45. Mironenko, R.M.; Belskaya, O.B.; Gulyaeva, T.I.; Nizovskii, A.I.; Kalinkin, A.V.; Bukhtiyarov, V.I.; Lavrenov, A.V.; Likholobov, V.A. Effect of the nature of carbon support on the formation of active sites in $\mathrm{Pd} / \mathrm{C}$ and $\mathrm{Ru} / \mathrm{C}$ catalysts for hydrogenation of furfural. Catal. Today 2015, 249, 145-152. [CrossRef]

46. Mironenko, R.M.; Belskaya, O.B.; Gulyaeva, T.I.; Trenikhin, M.V.; Likholobov, V.A. Palladium nanoparticles supported on carbon nanoglobules as efficient catalysts for obtaining benzocaine via selective hydrogenation of ethyl 4-nitrobenzoate. Catal. Commun. 2018, 114, 46-50. [CrossRef]

47. Tengco, J.M.M.; Lugo-José, Y.K.; Monnier, J.R.; Regalbuto, J.R. Chemisorption-XRD particle size discrepancy of carbon supported palladium: Carbon decoration of Pd? Catal. Today 2015, 246, 9-14. [CrossRef] 
48. Schmitz, E.; Eichhorn, I. Acetals and hemiacetals. In The Chemistry of the Ether Linkage; Patai, S., Ed.; Interscience Publishers: London, UK, 1967; pp. 309-351.

49. Stakheev, A.Y.; Kustov, L.M. Effects of the support on the morphology and electronic properties of supported metal clusters: Modern concepts and progress in 1990s. Appl. Catal. A Gen. 1999, 188, 3-35. [CrossRef]

50. Beletskaya, I.; Tyurin, V. Recyclable Nanostructured Catalytic Systems in Modern Environmentally Friendly Organic Synthesis. Molecules 2010, 15, 4792-4814. [CrossRef] [PubMed]

51. Bondarenko, G.N.; Ganina, O.G.; Sharma, R.K.; Beletskaya, I.P. Catalytic activity of Pd catalysts on different supports in hydrogenation of 1-phenylethenylphosphonic acid. Russ. Chem. Bull. Int. Ed. 2014, 63, 1856-1859. [CrossRef]

52. Hegedus, L.L.; McCabe, R.W. Catalyst Poisoning. Catal. Rev. Sci. Eng. 1981, 23, 377-476. [CrossRef]

53. Argyle, M.D.; Bartholomew, C.H. Heterogeneous Catalyst Deactivation and Regeneration: A Review. Catalysts 2015, 5, 145-269. [CrossRef]

54. Yakukhnov, S.A.; Pentsak, E.O.; Galkin, K.I.; Mironenko, R.M.; Drozdov, V.A.; Likholobov, V.A.; Ananikov, V.P. Rapid “Mix-andStir" Preparation of Well-Defined Palladium on Carbon Catalysts for Efficient Practical Use. ChemCatChem 2018, 10, $1869-1873$. [CrossRef]

55. Pinna, F.; Menegazzo, F.; Signoretto, M.; Canton, P.; Fagherazzi, G.; Pernicone, N. Consecutive hydrogenation of benzaldehyde over Pd catalysts: Influence of supports and sulfur poisoning. Appl. Catal. A: Gen. 2001, 219, 195-200. [CrossRef]

56. Fagherazzi, G.; Canton, P.; Riello, P.; Pernicone, N.; Pinna, F.; Battagliarin, M. Nanostructural Features of Pd/C Catalysts Investigated by Physical Methods: A Reference for Chemisorption Analysis. Langmuir 2000, 16, 4539-4546. [CrossRef]

57. Bergeret, G.; Gallezot, P. Particle Size and Dispersion Measurements. In Handbook of Heterogeneous Catalysis, 2nd ed.; Ertl, G., Knözinger, H., Schüth, F., Weitkamp, J., Eds.; Wiley-VCH: Weinheim, Germany, 2008; pp. 738-765.

58. Matyi, R.J.; Schwartz, L.H.; Butt, J.B. Particle Size, Particle Size Distribution, and Related Measurements of Supported Metal Catalysts. Catal. Rev. Sci. Eng. 1987, 29, 41-99. [CrossRef]

59. Hoye, T.R.; Eklov, B.M.; Ryba, T.D.; Voloshin, M.; Yao, L.J. No-D NMR (No-Deuterium Proton NMR) Spectroscopy: A Simple Yet Powerful Method for Analyzing Reaction and Reagent Solutions. Org. Lett. 2004, 6, 953-956. [CrossRef]

60. Hanson, J.E. NMR Spectroscopy in Nondeuterated Solvents (No-D NMR): Applications in the Undergraduate Organic Laboratory. In NMR Spectroscopy in the Undergraduate Curriculum; Soulsby, D., Anna, L.J., Wallner, A.S., Eds.; American Chemical Society: Washington, DC, USA, 2013; pp. 69-81. 